\title{
Towards Dialogue through a Holistic Measuring Framework \\ - The Impact of Social Media on Risk Communication in the Covid-19
}

\begin{abstract}
Design/methodology/approach

The impact of social media on risk communication is measured by the correlation between "speak from power" and "speak to power" levels, where the former primarily spoke to two facets of the risk communication process - rapidness and attentiveness, and the latter was benchmarked against popularity and commitment. The framework was empirically validated with data relating to Covid-19 risk communication in 25,024 selected posts on 17 official provincial Weibo accounts in China.
\end{abstract}

\section{Purpose}

Despite the huge potential of social media, its functionality and impact for enhanced risk communication remain unclear. Drawing on dialogic theory by integrating both "speak from power" and "speak to power" measurements, the article proposes a systematic framework to address this issue.

\section{Findings}

The analysis results suggest the relationship between the "speak from power" and "speak to power" is mixed rather than causality, which confirms that neither the outcome-centric nor the process-centric method alone cannot render a full picture of government-public interconnectivity. Besides, the proposed interconnectivity matrix reveals that the two provinces have evidenced the formation of government-public mutuality, which provides empirical evidence that dialogic relationships could exist in social media under the circumstance.

\section{Originality/value}


Our study proposed a prototype framework that underlines the need that the impact of social media on risk communication should and must be assessed through a combination of process and outcome, or interconnectivity. We further divide the impact of social media on risk communication into dialogue enabler, "speak from power" booster, "speak to power" channel, and mass media alternative.

Keywords: Social media; Risk communication; Dialogic theory, Covid-19

\section{Introduction}

Risk communication is the interactive exchange of information, advice, and opinions between the government and the public who face a threat, to disseminate situational awareness, recognize public actual needs, and enable informed decision-making. Given that emergencies are often fraught with uncertainty, confusion, and urgency (DiClemente \& Jackson, 2016), it is important that during the risk communication, the government officials must be responsive, credible (Tolbert \& Mossberger, 2006) while also persuading the public to be supportive of rules or regulations and stay away from rumor or fake messages, to minimize adverse outcomes. At the height of the pandemic, for instance, the failure of proper risk communication of the unprecedented measures (e.g., home isolation, city lockdown) introduced in a bid to curb the spread of Covid-19 has caused panic distress (e.g., the panic-buying), which may even evolve into societal chaos (Torero, 2020). Pearce (2003) observed that appropriate risk communication is the premise of a government's success in disaster management, therefore leading to the necessity to better communicate with the public to enable informed decision-making and assuage the psychological impacts (such as stress, frustration, dissatisfaction, and feelings of loss of control) caused by information uncertainty and asymmetry (Bucher et al., 2013). 
Risk communication has been further enhanced by the introduction of social media. In the mass media, traditional risk communication is considered as unidirectional information dissemination (Agostino \& Arnaboldi, 2016). Hand and Ching (2011) referred to this as to "speak from power", whereby members of the public are passive information recipients. Social media is believed to boost the "speak from power" capability because its flattened networked structure allows information to be updated in a highly prompt manner (Al-Saggaf \& Simmons, 2015) and makes it accessible to a wide range of audiences (Dabner, 2012), with 1.90 billion users on Facebook (Facebook, 2021) and 224 million on Weibo (WeiboCorporation, 2020), for instance. Moreover, an increasing number of recent studies (Mergel, 2013; Yan \& Pedraza - Martinez, 2019; Zheng \& Zheng, 2014) has suggested that social media has the potential to transform the prevailing but less desirable risk communication mode of "speak from power" into a "speak to power" approach (Hand \& Ching, 2011), which helps enhance information transparency with the public and formulate a public-to-government feedback loop (Picazo-Vela, Gutiérrez-Martínez, \& LunaReyes, 2012), ultimately leading to a desirable outcome of government trust (Wang \& Wan Wart, 2007). All combined, social media is believed to influence risk communication not only in its compelling advantage in its boost in "speak from power", but also the unique "speak to power" potential it can bring for risk communication, consequently receiving a wide spectrum of scholarly attention in the research community (Feeney \& Welch, 2012; Kim, Park, \& Rho, 2015; Ma, 2013).

Despite extensive theoretical studies positing that social media can facilitate interactions in terms of "speak to power" (Chen et al., 2020; Wirtz and Zimbres 2018; Das and Dutta 2021), the dialogic potential of social media in risk communication has not been fully achieved in practice (McAllister-Spooner, 2009; Sommerfeldt \& Yang, 2018). A few previous attempts have been made by scholars, such as Zheng and Zheng (2014), Ki and Nekmat (2014), Yan (2020), etc. However, 
the government and the public are two asymmetric entities, and none of these studies covered emergencies. The insights, therefore, cannot be readily applied in either asymmetric entities or emergencies, calling for immediate response. Further, the difficulty in understanding the dialogic potential of social media on risk communication is compounded given that it is not automatically fostered from one-off sporadic interactions but substantial back-and-forth interactions, making previous studies that based on either "speak from power" or "speak to power" inconclusive (Beaunoyer, Dupéré, \& Guitton, 2020). Specifically, a genuine dialogue requires investigating how "speak from power" and "speak to power" are correlated, thus requiring revisiting of behavior from both the public and government sides. A need, therefore, emerges to integrate the two dimensions to render the pointers which dialogic-oriented social media can pursue in risk communication with the over-arching research question:

How can integrating both "speak from power" and "speak to power" phases reveal the

\section{impact of social media on risk communication?}

In this research, we aim to investigate the interconnectivity between government action and public response through evaluating the level of "speak from power" and "speak to power" in risk communication. Further, an enhanced understanding of interconnectivity is deemed a starting point to develop a broader repertoire of strategies to exploit the benefits of social media in risk communication (Feeney \& Porumbescu, 2020). This study's contributions are twofold: (1) it incorporates "speak from power" and "speak to power" to provide a better understanding of the impact of social media on risk communication, further facilitating government's strategies development in risk; and (2) Provides nuanced insights into government-public dialogic relationship establishment, giving rise to policy notes on improving government transparency in the digital era. 
The remainder of this article is structured as follows. The background to this research and related literature are presented in Section Two, followed by the introduction of the prototype framework and methodology of the study in Section Three and Section Four, respectively. We verified and refined the framework with empirical data, set out in Section Five, with the discussion found in Section Six. The study concludes with a discussion of its implications in the final section.

\section{Literature review}

\subsection{Social media's impact on risk communication}

Communication is generally referred to as the conveyance of messages by means of exchanging thoughts, ideas, or information to the masses, the public, or niche audiences (Blumler \& Gurevitch, 2002; Irwin, 2021). Specific activities undertaken during an emergency situation for similar purposes are understood as risk communication (Ju, Ohs, Park, \& Hinsley, 2021). To this end, activities often involve the exchange of real-time information, advice, and opinions between experts and people facing threats to their health or economic or social well-being (DiClemente \& Jackson, 2016; Şirin \& Özkan, 2021). Risk communication mainly focuses on mustering and information sharing activity between the government and the public. In addition to many other communication methods (e.g., face-to-face, telephone, commercial radio, commercial television) (Lindell \& Perry, 1992), this study mainly focuses on risk communication on social media, such as Facebook, Twitter, and Weibo.

Social media has been exploited as a prevailing platform for communication because it supports wide information accessibility (Dabner, 2012), timely information updates (Al-Saggaf \& Simmons, 2015), and interactions among users (Tolbert \& Mossberger, 2006). First, the information accessibility of social media is highlighted in numerous studies (Borrino, Furini, \& Roccetti, 2009; Dabner, 2012; Tajudeen, Jaafar, \& Sulaiman, 2016). In general, social media sites 
are prone to facilitating the spread of information to their audiences, which can have a positive impact on information accessibility (Tajudeen et al., 2016). Particularly for disadvantaged groups, such as the disabled and seniors, social media enables users to access, perceive, and understand information (Borrino et al., 2009). Second, social media provides an "always-on" environment for information exchange (Xu, Kang, Song, \& Clarke, 2015), making instant communication possible (Bekkers, Edwards, Moody, \& Beunders, 2011). Meanwhile, its flattened networked structure allows information to be updated in a highly prompt manner (Al-Saggaf \& Simmons, 2015). As far as emergencies are concerned, underneath the descriptive advantages that social media has to offer, the extensive literature on risk communication through social media documents cases involves, for example, identification of missing people (Palen \& Liu, 2007) and mapping of hazards and risks (Pourebrahim, Sultana, Edwards, Gochanour, \& Mohanty, 2019). Social media has thus been extensively utilized in various situations relating to natural hazards and humaninduced disasters, establishing itself as a resourceful risk communication channel (Silver \& Matthews, 2017).

In addition, social media is identified with the key strength of triggering interaction between corresponding parties at a relatively low cost. Scholars (e.g., Bélanger and Carter, 2008; Welch et al., 2005; West, 2004) agree that social media is a cornerstone for public-driven information and service and speedy and convenient interactions. For instance, Warren, Sulaiman, and Jaafar (2014) asserted that social media has re-defined communication, providing its audience with the opportunity to spread social causes and participate in digital activism on various issues. Such an approach supports Mergel (2013) assertion that social media represents an effective way to attract the audience to engage, interact, and collaborate. Bertot et al. (2012) took a step further, identifying four key areas where social media exerts impact - collaboration, participation, empowerment, and 
real-time interaction. A similar study was undertaken by Medaglia and Zheng (2017), who argued that social media has increased communication in terms of responsiveness, information delivery, and service provision. Particularly during disasters, many scholars believed that risk communication can leverage social media as an enhanced interactive communication. Recognizing its merits, numerous studies are investigating government-public interactions in response to natural disasters (Lovari \& Bowen, 2019) as well as the ongoing Covid-19 pandemic (Liao et al., 2020).

In all, empowered by information technology, the participatory communication structure (Alvarez \& Hall, 2003) is believed to have the potential to encourage government-public interactions (Ksiazek, Peer, \& Lessard, 2016), but evidence on such interactions remains piecemeal and inconclusive. Thus, it is necessary to revisit the literature on the evaluation of the governmentpublic interactions.

\subsection{Evaluation of government-public interconnectivity}

To better understand government-public interactions, Rowe and Frewer (2000) took the first step, introducing a prototype framework to measure public activity in communication in terms of public participation. They re-categorized public activity into two levels - public communication and public participation. While public communication refers to a one-way "speak from power" information flow, public participation is characterized by "speak to power" public feedback. There are different derivatives of this classic formulation, such as that of Lee and Kwak (2012), who extend the evaluation framework to more levels, such as transparency, participation, and collaboration. These studies examine interactions between government and public participation through perceptions of administrative experts (Wang \& Wan Wart, 2007) rather than the real public. To address this limitation, other scholarship leverages stakeholder theory (Bonsón \& Ratkai, 2013) 
to include the public as survey respondents. Welch, Hinnant, and Moon (2005) explored the interactions between the government and the public on websites using surveys from internet users. Tolbert and Mossberger (2006) adopted a similar approach to investigate the responsiveness and accessibility of government through a telephone survey of 815 government website users. However, Haro-de-Rosario, Sáez-Martín, and del Carmen Caba-Pérez (2018) argued that the questionnaire-based method is based on surveyors' perceptions, suggesting that interactions between government and citizens are not directly examined. Instead, social media platforms such as Facebook, Twitter, and Weibo (Agostino \& Arnaboldi, 2016; Bonsón \& Ratkai, 2013; Gerlitz \& Helmond, 2013; Pérez, Bolívar, \& Hernández, 2012) have profiles (enabling users to, for example, like, share, and comment) that can directly reflect public activity levels on social media (Agostino \& Arnaboldi, 2016; Bonsón \& Ratkai, 2013; Haro-de-Rosario et al., 2018), which is more objective.

Further, most of the studies discussed here treat communication as a two-step procedure "speak from power" as the process and "speak to power" as the outcome (Agostino \& Arnaboldi, 2016; Bonsón \& Ratkai, 2013; Haro-de-Rosario et al., 2018). However, in a broader context, dialogic relationship establishment, rather than "speak to power", is the ultimate goal for communication (Bertot, Jaeger, \& Hansen, 2012; Zavattaro \& Sementelli, 2014). This is because the government can treat "speak to power" as a starting point for soliciting public feedback, recognizing actual needs, and embrace the public in disaster management (Bovaird, 2007) rather than treating it as an end. As such, the full potential of social media in communication is more than a one-off interaction, instead involving substantial back-and-forth "speak from power" and "speak to power" interactions to establish interconnectivity. This is deemed to foster greater government accountability, transparency, and responsiveness (Tolbert \& Mossberger, 2006). Further, the 
relationship between "speak from power" (process) and "speak to power" (outcome) is more complex than causality, making the findings of outcome-centric studies fragmented and inconclusive. To this end, integrating "speak from power" (process) and "speak to power" (outcome) could provide more nuanced insights into their interconnectivity, thus providing more holistic findings relating to the contribution of social media to government-public interconnectivity.

\section{Evaluation framework}

\subsection{Theoretic background}

Dialogic theory, first proposed by Buber (1923) in the book I and Thou in 1923, is primarily concerned with the attitudes held by each communication partner in interactive settings. In his view, a genuine dialogue sees communication parties in an equal "I-and-you" relationship (I-Thou) rather than a skewed "I-to-object" (I-it) relationship. Buber aimed for cooperative communication, where openness, honesty, and respect are centered in the "I-Thou" relationship (Agozzino, 2015). Dialogue is the core concept derived from dialogic theory, which is defined as a product of negotiated discussion with inter-subjectivity: it does not mean agreement, but rather an openness, respect, and willingness to reach mutually satisfying positions (Kent \& Taylor, 1998). As a result of its flexibility and applicability, scholars have extensively discussed dialogic theory and utilized it as a theoretical foundation that exploits communication strategically to facilitate interpersonal and organization-individual communications such as the work by Rogers (1957), Noddings (1986), and Pearson (1990).

In the context of social media, the dialogic theory provides an important theoretical foundation to explain why it might elevate communication. Social media is believed to provide a new frontier for innovation in creating a real-time dialogue between organizations and the public. 
Kent and Taylor (1998) led the efforts to situate dialogue digitally. Their research aimed to provide a theoretical framework to enhance organization-public dialogic relationships through the World Wide Web. The authors proposed a framework comprising five principal strategies (the dialogic loop, usefulness of information, generation of return visits, intuitiveness/ease of interface, and conservation of visitors) to enable scholars to gauge the extent of dialogic communication. In a later study, Kent and Taylor (2002) further developed five over-arching tenets (mutuality, propinquity, empathy, risk, commitment, and interpretation) that encompass the implicit and explicit assumptions underlying the concept of dialogue. The dialogic principles have been applied to research exploring organizational types such as universities (Gordon \& Berhow, 2009), commercial companies (Rybalko \& Seltzer, 2010), and non-government organizations (Inauen, Schoeneborn, \& Scherer, 2011).

As initially conceived, with the help of social media in fostering a sense of connectedness amongst and between citizenry and government to build dialogic relationships (Bertot et al., 2012), social media platforms, such as Twitter and Weibo, assist governments in increasing capacity for communication (Zavattaro \& Sementelli, 2014). Nevertheless, empirical evidence on the dialogue, especially for handling the power imbalance between government and the public remains scant (McAllister-Spooner, 2009; Sommerfeldt \& Yang, 2018).

The dialogic relationship or interconnectivity does not form automatically either in social media or during risk communication. If the governments merely treat "speak from power" as the means for information dissemination for the emergency response or the citizens treat the "speak to power" as an outlet of voicing their fears, no dialogue would be established. Instead, true connectivity requires the generation of return visits (Kent \& Taylor, 2002) or mutuality (Kent \& Taylor, 2002) that is not fostered through one-off sporadic interactions but substantial back-and- 
forth ones. Therefore, it is important to evaluate the existence of such substantial interactions through integrating speak from power" and "speak to power".

\subsection{Evaluation Framework}

We integrated "speak from power" and "speak to power" (Figure 1) to verify the existence of government-public dialogue and to provide nuanced insights into the social media based risk communication.

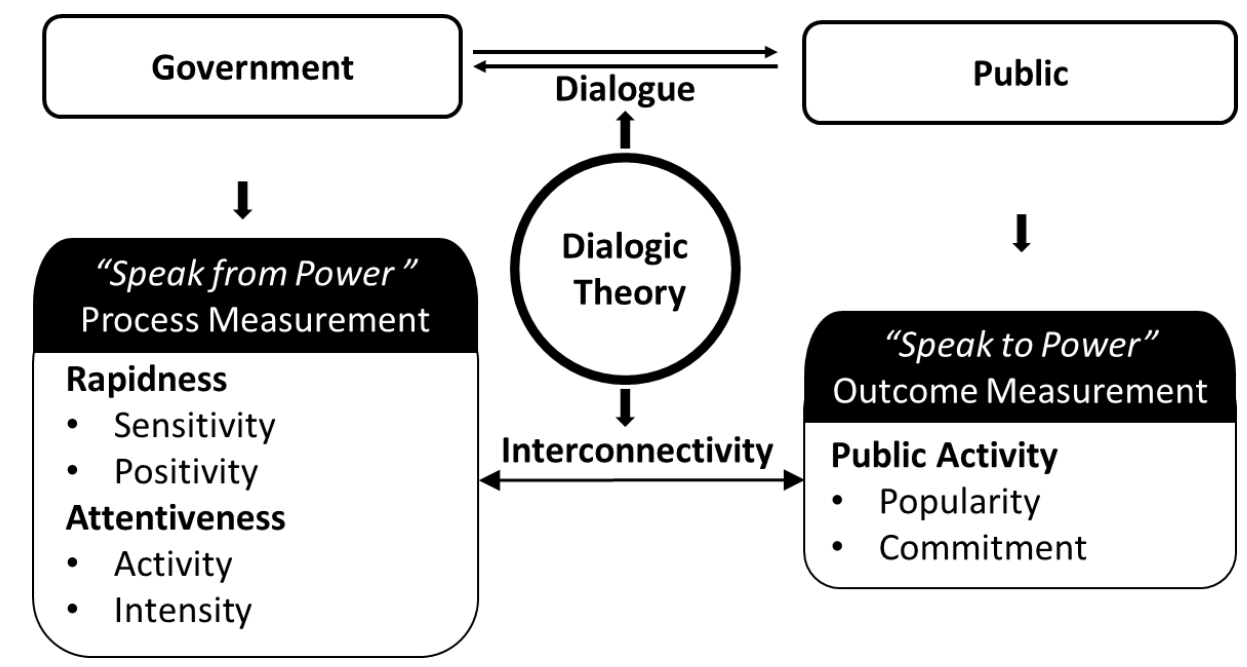

Figure 1 Measuring the government-public interconnectivity through integrating

"speak from power" and "Speak to power"

\subsection{Speak to power}

According to Kent and Taylor (1998), dialogue rests on a willingness to the conversation and the "speak to power" metric is designed to quantify the willingness from the public side in the risk communication. According to the dialogic theory, dialogue requires the generation of return visits (Kent \& Taylor, 1998) and mutuality (Kent \& Taylor, 2002). Publics' frequent visits can be deemed as a proxy indicating the information provided is useful, timely, and demanding, whereas their intention to "voice" can be deemed a benchmark if a comfortable or satisfying position is reached (Kent \& Taylor, 2002). Therefore, we adopted Popularity and Commitment from Agostino and 
Arnaboldi (2016) to quantify the users' activity in social media. Particularly in risk communication, Popularity is adopted to measure the level of the public's frequent involvement in the risk communication, which is the starting point of government-public dialogue. Commitment is adopted to measure the extent to which the public feels comfortable in the risk communication and voice their opinions and feelings.

\subsection{Speak from power}

Speak from power is designed to measure the willingness of the government to dialogue with the public. For the government, in risk communication, information dissemination is not the ultimate goal for risk communication, but providing useful, timely, and demanding information can be a gesture of being responsible, creditable, and treating the public in a mutual position (Kent \& Taylor, 1998). A responsible government in risk communication can be reflected by how fast and how many resources they put to respond. In the context of social media, based on the literature examined, Speak from power is measured by two dimensions, where rapidness (Shan, Wang, Li, \& Chen, 2012) measures the former and the attentiveness (Rishika, Kumar, Janakiraman, \& Bezawada, 2013) relates to the later.

As a sign of willingness to dialogue with the public, Rapidness, adopting from Shan et al. (2012), measures the speed quality of governmental action in the risk communication. Two dimensions of rapidness are considered, namely sensitivity, and positivity. Sensitivity, adopted from Snyder and Kelly (1977), is defined in this context as the proficiency with which the government can identify, perceive, and understand cues and contexts in an emergency and initiate dialogue with the public. Positivity, adopted from Mondak (1995), describes the state of governmental positive involvement in risk communication.

Attentiveness reflects the extent to how the government being responsible in risk 
communication. According to Kavanaugh et al. (2012), the government's responsibility can be identified as their behaviors in social media activity such as content preference and spikes. Thus, we further formulate two measurement dimensions. Activity reflects the government's preference for engaging with social media for risk communication, including the release of routine information and crisis information (Kavanaugh et al., 2012). Intensity, on the other hand, describes the extent to which the government is dedicated to important events (such as Covid-19, in this case) (Machmud, Irawan, Karinda, \& Susilo, 2021).

\section{Methodology}

\subsection{Data acquisition}

Alongside other popular leading social media platforms such as Facebook and Twitter, Weibo is one of the most influential social media providers in China, with 550 million monthly active users (WeiboCorporation, 2020), making it an appropriate candidate for understanding the impact of social media on risk communication, specifically in the Chinese context. The proposed framework is validated using the Weibo data in this study but is also deemed applicable for other social media platforms such as Facebook and Twitter.

The Weibo data was collected from the Sina Weibo Application Programming Interface (API). Using the API, we were able to collect Weibo posts from a user's timeline, which refers to a list of Weibo posts by a specific user. For each post on Weibo, attributes such as ID, Text, URL, Location, Date, Like, Comment, Share, Topic, and @User were retrieved and saved.

\subsection{Eligible criteria}

In this study, we organized the research with a specific focus on Weibo accounts that are officially operated by the information office of each provincial administrative unit. Practically, these official accounts act as proxies for risk communication initiatives by provincial governments in China. Notably, we ruled out official Weibo accounts operated by other government-owned 
agencies such as the People's Daily (operated by the People's Daily, an official newspaper of the central committee of the Communist Party of China) and China Daily (operated by China Daily, owned by the publicity department of the Communist Party of China rather than provincial units). We believe that their information release strategies differ significantly from the approaches examined here, as they are professional media outlets.

\subsection{Content analysis of crisis relevance}

While various messages were publicized through their Weibo accounts, this study only selected posts with contents directly pertaining to the specific event in question (Covid-19). Thus, as soon as the raw data was collected, we deployed SpaCy (Honnibal \& Montani, 2017) to identify event-related posts. SpaCy is an open-source library for advanced natural language processing, which supports Chinese and is therefore deemed appropriate for Chinese content analysis. The processing consisted of two main phases: pre-processing and training.

The pre-processing step aims to construct a high-frequency event corpus. For each Weibo post, the content is inputted for a series of three processing tasks - tokenization, part-of-speech tagging, and named entity recognition. The long sentences in each post were segmented into tokens and we then aggregated the tokens from all the posts as a corpus and ranked them according to their frequency. After the corpus was constructed, we reviewed the top 50 tokens and filtered out those not directly relevant to the event.

In the training phase, the training datasets are annotated manually based on whether or not they contained tokens in the high-frequency event corpus. Specifically, posts containing tokens in the high-frequency event corpus were annotated as 1 while others were annotated as 0 . The training datasets were subsequently inputted into a gradient loss-based prediction model in SpaCy. The training was an iterative process as part of which the model's predictions were compared against the reference annotations to estimate the gradient of the loss. The gradient of the loss was then 
used to calculate the gradient of the weights by means of backpropagation. After all the iterations, we saved the final model as the updated model for the evaluation datasets (sample scope). For the content analysis, we use the random sampling method to select $10 \%$ of datasets as the training dataset. The final high-frequency Covid-19 corpus is presented in Table 1.

\section{Table 1 Lists of high-frequency Covid-19 corpus}

\begin{tabular}{|c|c|}
\hline Category & Tokens in Chinese (English meaning) \\
\hline Disease name & $\begin{array}{l}\text { 新型肺炎(new pneumonia), 新型冠状(new coronavirus),新冠(coronavirus), 冠 } \\
\text { 状病毒 (coronavirus), 肺炎(pneumonia), Covid-19, Covid19, 病毒性肺炎 (viral } \\
\text { pneumonia), 疫情(epidemic), 传染病(pandemic). }\end{array}$ \\
\hline $\begin{array}{l}\text { Infection } \\
\text { prevention and } \\
\quad \text { control }\end{array}$ & $\begin{array}{l}\text { 人传人(human-to-human transmission), 潜伏期 (incubation), 超级传播者 (super } \\
\text { spreader), 密切接触者 (close contact), 发病 (morbidity), 输入性病例 (imported } \\
\text { case), 疫情 (epidemic), 发热病人 (patient with fever), 核酸检测 (nucleic acid } \\
\text { testing), 口罩紧缺(mask shortage), 防护服紧缺(protective clothing shortage; 酒 } \\
\text { 精紧缺(shortage of disinfectant alcohol), N95紧缺 (N95 mask shortage), 防护面 } \\
\text { 罩紧缺(protective mask shortage), 护目镜紧缺 (goggles shortage), 床位紧缺 } \\
\text { (shortage of hospital beds). }\end{array}$ \\
\hline $\begin{array}{c}\text { Policy } \\
\text { initiatives }\end{array}$ & $\begin{array}{c}\text { 封城 (city lockdown), 隔离(quarantine), 居家(stay-at-home order), 社交距离 } \\
\text { (social distancing), 应急医院 (makeshift hospital), 突发公共卫生事件 (public } \\
\text { health emergency), 聚集 (mass gatherings), 两周观察期 (two-week observation } \\
\text { period). }\end{array}$ \\
\hline
\end{tabular}

\subsection{Outcome and process measurement}

To better understand the interconnectivity between the government and the public in social media during the risk communication, measuring the process and outcome is a premise. As such, the metric is developed (Table 2).

For the outcome measurement, from different evaluation metrics (Agostino \& Arnaboldi, 2016; Bonsón \& Ratkai, 2013; Gerlitz \& Helmond, 2013; Pérez et al., 2012), we adopted a metric developed by Agostino and Arnaboldi (2016). Specifically, popularity is determined using the ratio between "total likes" per post and the total number of followers of the Weibo account. Commitment, on the other hand, is determined by the ratio of combined "total shares" and "total comments" per post and the total number of followers of the Weibo account. 
Table 2 Measurement matrices

\begin{tabular}{|c|c|c|c|}
\hline $\begin{array}{c}\text { Measurement } \\
\text { level }\end{array}$ & Description & Notation & Metrics used for Weibo \\
\hline \multicolumn{4}{|c|}{ Process: Rapidness of response } \\
\hline \multirow[t]{2}{*}{ Sensitivity } & $\begin{array}{l}\text { Describes the proficiency } \\
\text { with which government- } \\
\text { owned social media } \\
\text { platforms can identify, } \\
\text { perceive, and understand } \\
\text { cues and contexts in an }\end{array}$ & \multirow[t]{2}{*}{$P_{\text {sensitivity }}$} & \multirow[t]{2}{*}{$\begin{array}{l}\text { The inverse of the duration between the first } \\
\text { routine post and the first event post. In this } \\
\text { study, according to SCIO, Covid-19 was } \\
\text { first reported on December } 27,2019 . \\
\qquad \frac{1}{T_{\text {FirstPost }}-T_{\text {FirstEvent }}}\end{array}$} \\
\hline & emergency. & & \\
\hline \multirow[t]{2}{*}{ Positivity } & $\begin{array}{l}\text { Describes a state of positive } \\
\text { involvement in risk } \\
\text { communication. }\end{array}$ & \multirow[t]{2}{*}{$P_{\text {positivity }}$} & $\begin{array}{l}\text { The inverse of the duration between the } \\
\text { first event post and the first time the event- } \\
\text { relevant post ratio reaches a threshold } \delta \text { - } \\
\text { in this study we set the threshold at } 0.50 \text {. } \\
1\end{array}$ \\
\hline & & & $\overline{T\left(\rho_{\text {Event }} \geq \delta\right)-T_{\text {FirstPost }}+1}$ \\
\hline \multicolumn{4}{|c|}{ Process: Attentiveness of response } \\
\hline Activity & $\begin{array}{l}\text { Describes the actions of a } \\
\text { Weibo account relating to } \\
\text { risk communication, } \\
\text { including daily information } \\
\text { and crisis information. }\end{array}$ & $P_{\text {activity }}$ & $\begin{array}{l}\text { The average number of daily posts since } \\
\text { the first event post was released. }\end{array}$ \\
\hline \multirow[t]{2}{*}{ Intensity } & \multirow{2}{*}{$\begin{array}{l}\text { Describes the degree to } \\
\text { which the Weibo account is } \\
\text { dedicated to risk } \\
\text { communication. }\end{array}$} & \multirow{2}{*}{$P_{\text {Intensity }}$} & $\begin{array}{l}\text { The ratio of event posts to all daily posts. } \\
\qquad \underline{\mu_{\text {EventPost }}}\end{array}$ \\
\hline & & & $\mu_{\text {DailyPost }}$ \\
\hline \multicolumn{4}{|c|}{ Outcome: Public activity } \\
\hline \multirow{2}{*}{ Popularity } & \multirow{2}{*}{$\begin{array}{l}\text { Effectiveness of risk } \\
\text { communication in attracting } \\
\text { public attention to Weibo. }\end{array}$} & \multirow{2}{*}{$O_{\text {popularity }}$} & Total Likes \\
\hline & & & $\overline{\text { Total Posts } \cdot \text { Total Followers }} \times 10^{\circ}$ \\
\hline \multirow{2}{*}{ Commitment } & \multirow{2}{*}{$\begin{array}{l}\text { Effectiveness of risk } \\
\text { communication in initiating } \\
\text { public feedback. }\end{array}$} & \multirow{2}{*}{$O_{\text {commitment }}$} & Total Shares + Total Comments \\
\hline & & & $\overline{\text { Total Posts } \cdot \text { Total Followers }} \times 1$ \\
\hline
\end{tabular}

For the process measurement, based on the literature examined, no well-established measurement metrics address our special context, meaning that an operable measurement metric was further developed. In the process rapidness, sensitivity is computed as the inverse of the duration between the first routine post and the first event post, where the event relevance is determined using the machine learning method already described in the methodology section. On the other hand, the term positivity is computed as the inverse of the duration between the first event post and the first time an event-relevant post ratio reaches a threshold $\delta$. In this study we set the 
threshold at 0.50 , indicating that the number of event posts exceeds the number of routine posts. For the process attentiveness, based on the work of Kavanaugh et al. (2012), activity is computed as the average number of daily posts since the first event post was released, while intensity is measured as the ratio of event posts to all posts.

\section{Results}

\subsection{Background}

Covid-19 has ravaged the globe on an unprecedented scale. Along with other countries affected by the pandemic, China has been working around the clock in a resolute battle to curb the spread of the disease and prevent it from re-surging. Specifically, in China, Covid-19 was first officially identified by the Wuhan Municipal Health Commission on December 31, 2019 (NRP.org, 2020b), which was selected as the starting date of the investigation. No new confirmed cases were first reported in Hubei on March 18, the worst-hit area in China, which was correspondingly selected as the end date for the data collection (Nature, 2020).

Applying inter-rater policy, each author conducted a preliminary search on their own and concluded that 20 of the 34 provincial administrative units in China so far have registered an official Weibo account for information release (Table 3). We removed the Hebei, Hunan, and Sichuan accounts and retained the remaining 17 as the focal sample because the posts from these three accounts did not cover the entire research window from the official declaration of the outbreak on January 21 to the downgrading of the emergency response in each province. The detailed demographics and characteristics of each province are provided in Appendix 1.

\section{Table 3 Scope of the study}

\begin{tabular}{c|c|c}
\hline & Sample scope $*$ & Out-of-sample \\
\hline $\begin{array}{c}\text { Total } \\
\text { numbers }\end{array}$ & 17 & 17 \\
\hline
\end{tabular}




\begin{tabular}{c|c|c}
\hline $\begin{array}{c}\text { Provincial } \\
\text { administrative } \\
\text { unit }\end{array}$ & $\begin{array}{c}\text { Beijing, Tianjin, Shanghai, Chongqing, } \\
\text { Henan, Hubei, Jiangsu, Jiangxi, Jilin, } \\
\text { Heilongjiang, Shanxi, Shandong, Qinghai, } \\
\text { Guangdong, Guizhou, Zhejiang, Xinjiang }\end{array}$ & $\begin{array}{c}\text { Hebei**, Hunan**, Liaoning, } \\
\text { Shaanxi, Anhui, Hainan, Fujian, } \\
\text { Taiwan, Gansu, Yunnan, Sichuan**, } \\
\text { Tibet, Ningxia, Guangxi, Inner } \\
\text { Mongolia, Hong Kong, Macau }\end{array}$ \\
\hline
\end{tabular}

Note: * The social media accounts selected for analysis in this study are Weibo accounts, which are officially operated by the Information Office of the government in each provincial administrative unit, respectively.

**Hebei, Hunan, and Sichuan do have official Weibo accounts, but none of these posts information covers the entire epidemic period, and therefore these accounts are not included in this study.

\subsection{Results: Descriptive statistics}

Figure 2 depicted the daily number of posts, likes per post, shares per post, and comments per

post for all 17 sample provincial administrative Weibo accounts. Comparing the data before and after January 20, when the human-to-human transmission was first announced in China, we found that the average number of daily posts remained static before January 20. However, this significantly increased from 240.21 to 320.05 - a $33.24 \%$ increased ratio. Similarly, the average number of daily likes, shares, and comments increased by $337 \%, 1204 \%$, and $258 \%$, respectively. A significant decline then took place in the daily number of posts alongside a reverse jump in the number of likes per post, shares per post, and comments per post from January 20 to January 25 . During this period, all levels of provincial government took immediate measures. On January 20, President Xi Jinping ordered "resolute efforts" to curb the spread of the novel coronavirus that caused cases of pneumonia (XinhuaNet, 2020b). On January 23, Wuhan city was sealed (NRP.org, 2020a), when three provinces first announced a Level 1 emergency response. By January 25, 30 of the 34 provincial governments joined the response (XinhuaNet, 2020a), all taking a strict stance regarding Weibo posts and carefully reviewing the messages being circulated. Moreover, the daily number of posts bounced back on January 26 and then gradually increased. In the meantime, the number of likes, shares, and comments per post decreased. The second peak in the number of likes, shares, and comments per post occurred on January 31, the date after the World Health Organization (WHO) declared coronavirus "a public health emergency of international concern" (WHO, 2020). 


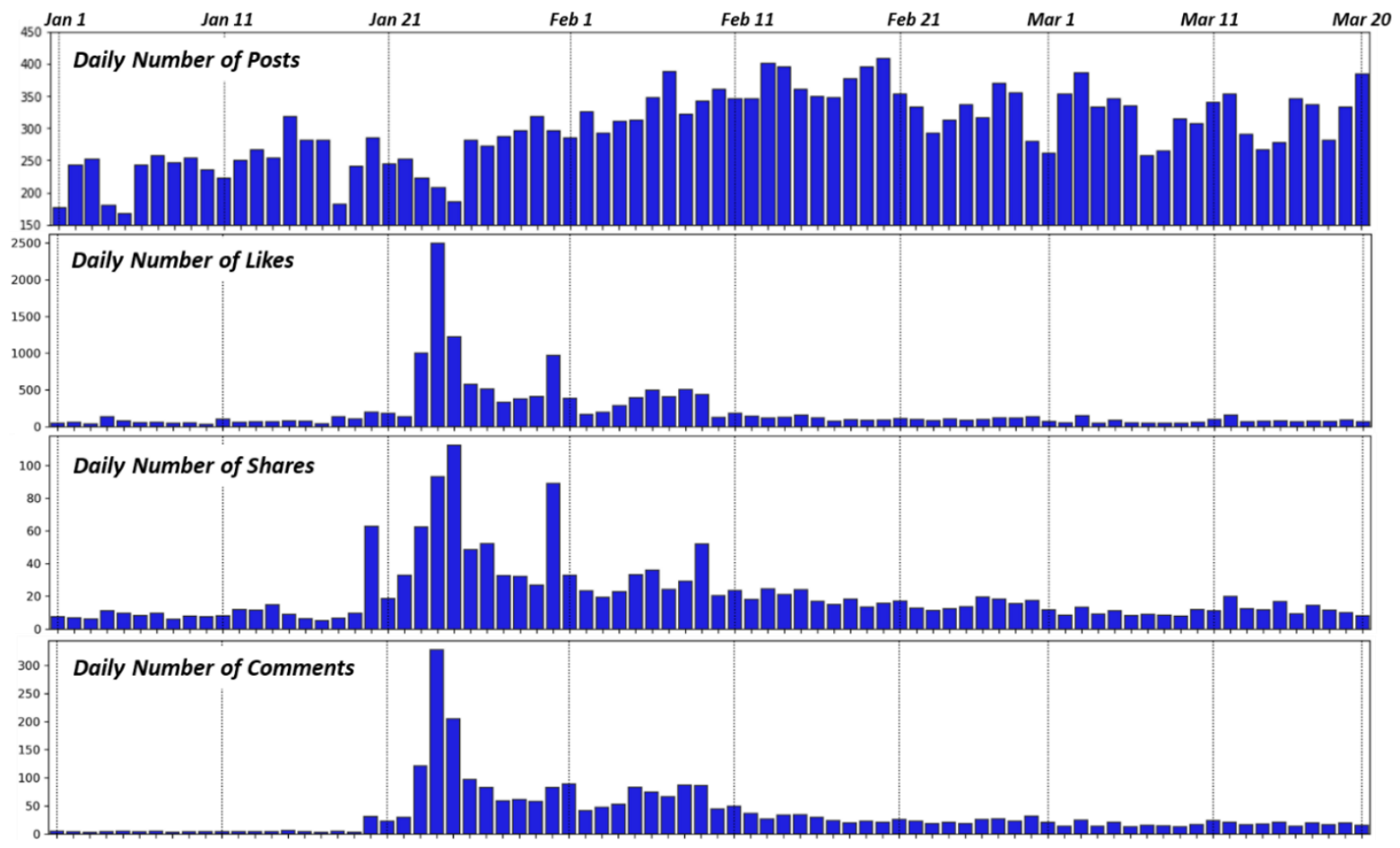

Figure 2 Statistics for 17 provincial governments and their engagement of the public

\section{through Weibo}

Table 4 summarizes the preliminary results of both process and outcome, based on the proposed framework of the 17 provinces. It implies a connection between government information release on social media and public attention on the epidemic, as the Weibo accounts with relatively high levels of popularity and commitment are more likely to perform better in rapidness and attentiveness. Aside from this connection, however, it does not provide more nuanced insights. For instance, the preliminary result does not fully capture a picture of whether the increase in risk communication activity or intensity (process) would lead to an increase in public activity (outcome) or extend the relationship between them. More importantly, some inverse and asynchronous trends stemming from the period, as depicted in Figure 2, remain unclear and perplexing. For instance, the decrease in risk communication activities on social media during the period from January 20 to January 25 surprisingly witnessed the first peak in public activity, while the latter increase in 
risk communication activities after February 11 took place alongside an increase in public participation activities. This contradictory scenario reinforces the importance of understanding the interconnectivity between the government and the public - we set out further quantities and methods below:

Table 4 Measures of process and outcome

\begin{tabular}{|c|c|c|c|c|c|c|}
\hline \multirow{2}{*}{ Province } & \multicolumn{2}{|c|}{ Process rapidness } & \multicolumn{2}{|c|}{ Process attentiveness } & \multicolumn{2}{|c|}{ Outcome } \\
\hline & $T_{\text {FirstEven }}$ & $T\left(\rho_{\text {Event }} \geq 0.5\right)$ & $P_{\text {activity }}$ & $P_{\text {Intensity }}$ & $O_{\text {popularity }}$ & $O_{\text {commitment }}$ \\
\hline Beijing & Jan-20 & 4 & 11.81 & 0.49 & 28.04 & 7.56 \\
\hline Tianjin & Jan-20 & 5 & 13.34 & 0.27 & 53.25 & 21.71 \\
\hline Shanghai & Jan-20 & 4 & 7.15 & 0.37 & 180.20 & 48.54 \\
\hline Chongqing & Jan-20 & 3 & 10.05 & 0.47 & 290.69 & 69.05 \\
\hline Henan & Feb-13 & 1 & 1.22 & 0.63 & 1.07 & 1.08 \\
\hline Hubei & Jan-3 & 21 & 9.51 & 0.47 & 12.06 & 9.54 \\
\hline Jiangsu & Jan-20 & 4 & 6.21 & 0.34 & 13.14 & 6.79 \\
\hline Jiangxi & Jan-21 & 3 & 15.22 & 0.42 & 134.03 & 34.78 \\
\hline Jilin & Jan-21 & 0 & 2.64 & 0.33 & 271.75 & 85.03 \\
\hline Heilongjiang & Jan-18 & 0 & 8.53 & 0.55 & 110.35 & 41.34 \\
\hline Shanxi & Jan-20 & 7 & 11.10 & 0.39 & 461.47 & 116.77 \\
\hline Shandong & Jan-24 & 0 & 6.14 & 0.37 & 17.35 & 3.72 \\
\hline Qinghai & Jan-22 & 2 & 2.21 & 0.51 & 36.75 & 13.10 \\
\hline Guangdong & Jan-20 & 0 & 1.86 & 0.84 & 91.86 & 28.41 \\
\hline Guizhou & Jan-29 & 0 & 1.29 & 0.72 & 122.81 & 39.95 \\
\hline Zhejiang & Jan-20 & 6 & 3.40 & 0.40 & 208.29 & 66.38 \\
\hline Xinjiang & Jan-20 & 65 & 4.58 & 0.19 & 15.37 & 1.18 \\
\hline
\end{tabular}

\subsection{Public activity outcome matrix}

We adopted the social media engagement matrix proposed by Agostino and Arnaboldi (2016) to benchmark public activity on social media, as depicted in Figure 3. Four quadrants were defined by popularity and commitment, obtained from the Weibo data. Popularity describes the performance of one-way information dissemination from the government to citizens and is plotted on the X-axis, while two-way invective public activity level, expressed by commitment, is on the Y-axis. By positioning the mean values of both popularity and commitment as the reference value, four quadrants - leaders, engagers, ghosts, and chatterboxes - are identified to describe the different levels at which social media contributes to public activity. 


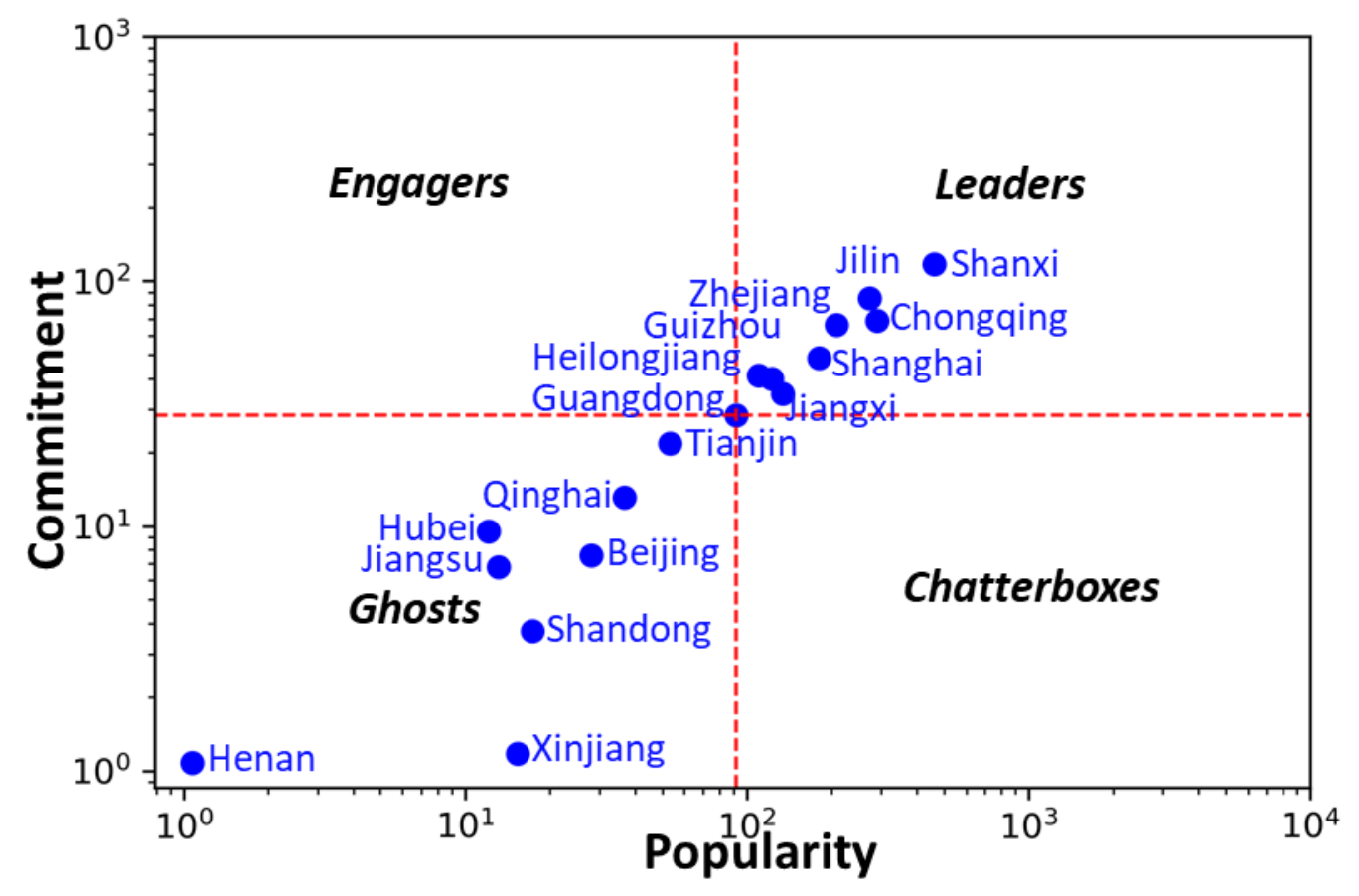

Figure 3 The outcome matrix

Leaders, in the top-right quadrant, are provincial Weibo accounts with high levels of popularity and commitment. This implies that information disseminated in these accounts has not only attracted the public's attention (indicated by likes) but also addressed their concerns and triggered their intentions to voice their opinions (indicated by shares and comments). This is the highest level of public feedback. Particularly during an emergency, shares and comments on social media are important channels through which emergency managers can solicit feedback.

Engagers, in the top-left quadrant, are provincial Weibo accounts with high levels of commitment, but low levels of popularity. This means that these provincial governments have established a certain level of information interaction with their followers - however, their follower numbers are limited. Ideally, engagers can improve their popularity by increasing activity. The biggest concern is whether social stratification exists among these followers as information release should not be discriminated against. If the followers only represent a small division of the target group in the hierarchy, the government also fails to support full risk communication. 
Chatterboxes, in the bottom-right quadrant of the matrix, represent Weibo accounts with high levels of popularity but low levels of commitment. This means that these provincial Weibo accounts have already attracted a considerable amount of public attention, but the information released is prone to be irrelevant to public concerns or non-interactive - dialogues between citizens and the government have not yet been formed.

Ghosts, in the bottom-left quadrant, are provincial accounts with low levels of both popularity and commitment. This implies that the public may not be aware of these accounts and they may therefore fail to trigger public feedback. As such, the value of social media is not exploited.

In contrast to the previous application (Agostino \& Arnaboldi, 2016), in a non-crisis scenario, where the provinces are more evenly distributed in the four quadrants of the engagement matrix, this research indicates that those provinces are primarily located within two quadrants (Leaders, Ghosts) for risk communication. This suggests a distinctive difference between the nature of routine communication and risk communication, reinforcing the notion that existing studies of routine communication must be extended to shed further light on emergency situations.

Further, in comparing this work with the research of Agostino and Arnaboldi (2016), Figure 3 implies a stronger correlation between popularity and commitment, suggesting an increased popularity-to-commitment conversion and further highlighting the importance of dialogic theory, which explores interconnectivity between the public and the government by understanding the behavior of both parties. Nevertheless, the outcome matrix (reflective of public behavior) alone fails to address specific governmental actions and strategies for risk communication, potentially leading to an increase in popularity-to-commitment conversion. We thus introduced the process measurement to address the two issues.

\subsection{The rapidness matrix}

The rapidness matrix represents the speed quality of governmental action on social media for 
risk communication. The matrix (Figure 4) is composed of four quadrants defined by response sensitivity and response positivity. The description and computation metrics for rapidness, sensitivity, and positivity are depicted in the methodology section and Table 2, respectively. Sensitivity is plotted on the $\mathrm{X}$-axis and positivity is plotted on the Y-axis. By positioning the mean values of both dimensions, the four quadrants were identified, corresponding to the speed quality of the response of each administrative unit.

Passive follower, in the bottom-left quadrant, is a province with low levels of both sensitivity and positivity. This implies that these provinces have a lagging awareness of the crisis and are unable to take proactive measures on social media for risk communication. No province was located in this quadrant.

Active follower, in the bottom-right of the response matrix, is a province with a high level of sensitivity but a low level of positivity. This implies that these provinces have quickly perceived and responded to emergency situations. However, if, for example, they are affected comparatively less, or to prevent unnecessary panic, they are less positively involved in social media for risk communication. Four provinces (e.g., Qinghai, Guizhou) sit in this quadrant.

Active responder, in the top-right quadrant, is a provincial Weibo account with high levels of both sensitivity and positivity. This means that, in relation to risk communication, these provincial governments are not only sensitive to but also actively engaged in posting Covid-19-related information to inform citizens and engage them in emergency response activity using social media. From the analysis, ten provinces were attributed to this quadrant, including the most economically advanced provincial administrative units, such as Beijing, Shanghai, and Guangdong. 


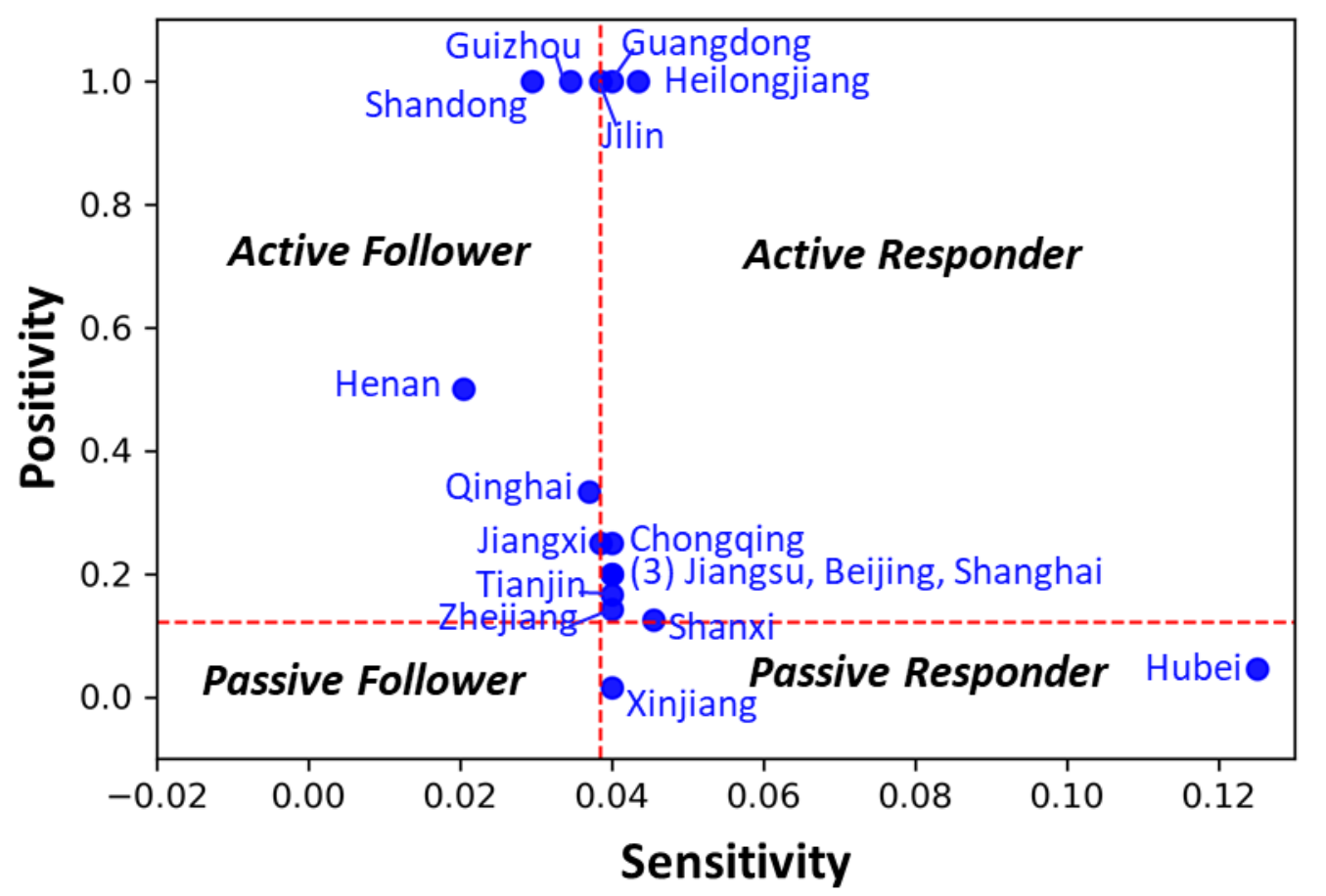

Figure 4 Process Rapidness Matrix

Passive responder, in the bottom-right quadrant, is a province with a high level of sensitivity but a low level of positivity. This means that although these governments are not sensitive they are active on social media for risk communication. Hubei, the province most affected by the pandemic, and Xinjiang, fell into this category. Particularly for Hubei, as a result of the nascent nature of Covid-19, there was much uncertainty in the first instance, and the local government took a prudent stance in the hope of providing information that was as accurate as possible. As a result, Hubei could choose to be stringent in circulating confirmed information rather than putting out excessive communications. However, as the epidemic developed, the government progressively grasped more details relating to Covid-19 and started to become active in informing the public of the potential health risks and recommended countermeasures to ensure government transparency.

\subsection{The attentiveness matrix}

Attentiveness represents governmental actions showing that they are paying attention to Covid-19. The attentiveness matrix (Figure 5) is composed of four quadrants defined by overall 
post activity and Covid-19-related post intensity. The description and computation metrics for attentiveness, activity, and intensity are depicted in the methodology section and Table 2. Activity is plotted on the $\mathrm{X}$-axis and intensity is plotted on the Y-axis. By positioning the mean values of both dimensions, the four quadrants corresponding to the extent of governmental involvement on social media for risk communication were identified.

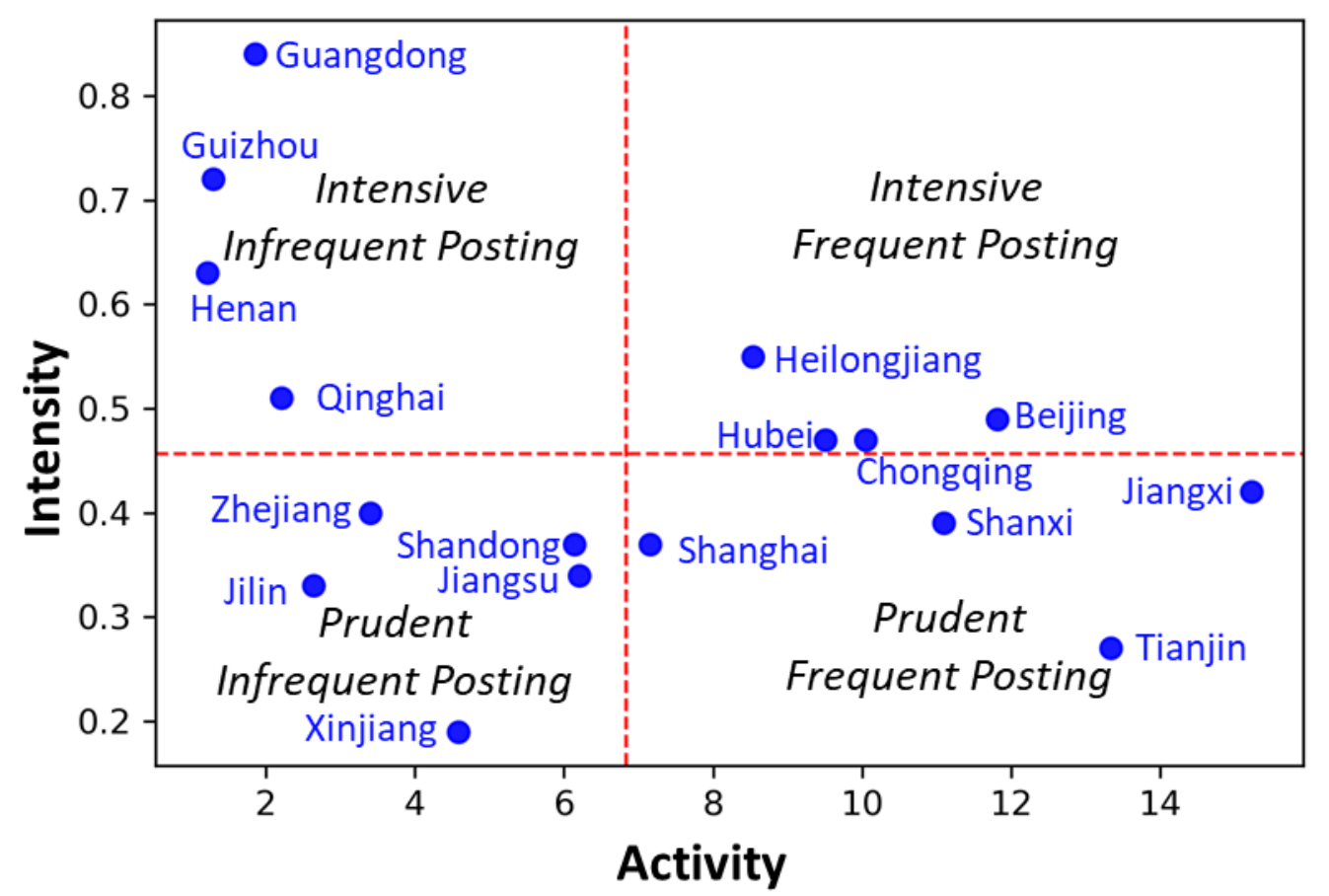

Figure 5 The Attentiveness Matrix

Intensive infrequent posting, in the top-left quadrant, refers to a low level of social media activity but a high level of crisis response intensity. This implies that social media is not employed in these provinces for routine communication, but for crisis response. For instance, Guangdong released only a couple of posts daily, in which the epidemic data was updated.

Prudent infrequent posting, in the bottom-left quadrant, refers to low levels of both activity and crisis response intensity. This implies that social media is not fully exploited for routine communication or crisis response. 
Intensive frequent posting, in the top-right quadrant, refers to high levels of both activity and crisis response intensity. This means that social media in these provinces is exploited because these provinces intensively focus on specific events while maintaining routine communication activity. Four provinces are located in this quadrant. For instance, Beijing is the capital as much more attention was given to this city, and Hubei, the most heavily hit area, was constantly under the spotlight. By increasing the amount and diversity of information, these provinces, therefore, aimed to improve the transparency of their crisis information to engage the public more and attract more responses.

Prudent frequent posting, in the bottom-right quadrant, refers to a high level of activity but a low level of crisis response intensity. This suggests that, for such provinces, social media is employed more for routine communication. One explanation for provinces adopting this strategy is that they have been lightly hit but are on the potential path of epidemic spread: Shanghai and Tianjin are two major destinations for the working population from Hubei while Chongqing and Jiangxi are adjacent to Hubei. To reduce unnecessary panic and anxiety in the public sphere, these provinces are prone to deliberately increasing the amount of risk communication on panic release, emotional motivation, and encouragement.

\subsection{Government-Public interconnectivity}

To better derive the government-public interconnectivity, the three matrices - response rapidness, response attentiveness, and the public activity matrix were aligned (Table 5) to provide

first observes on how to deploy interconnectivity between the process and the outcome to understand the impact of social media on risk communication. The "Speak from power" process level is plotted on X-axis and the "speak to power" outcome level is plotted on Y-axis. By positioning the high and low levels of both dimensions, the four quadrants corresponding to the 
impact of social media for risk communication were identified as depicted in Figure 6.

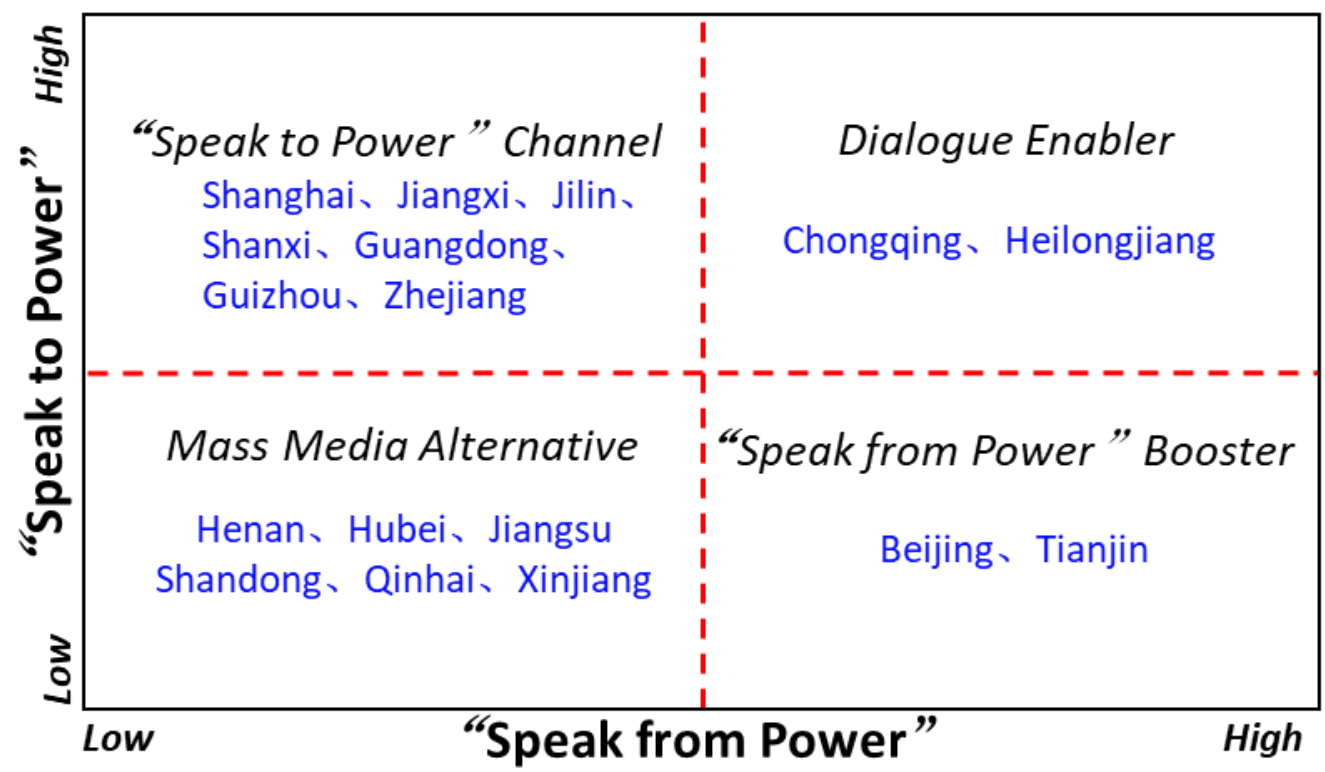

Figure 6 The Interconnectivity Matrix

Dialogue enabler, in the top-right quadrant, refers to high levels in both dimensions. This implies that social media has been fully exploited to extend accessibility and empower the public to voice during emergencies. Chongqing and Heilongjiang are located in this quadrant.

"Speak form power" booster, in the bottom-right quadrant, refers to a high level in "speak from power" but a low level in "speak to power". This suggested that the social media in these provinces are mainly deployed to boost information dissemination rather than solicit public feedback. Beijing and Tianjin are located in this quadrant.

"Speak to power" channel, in the top-left quadrant, refer to a low level in "speak from power" but a high level in "speak to power". This indicates that though the dialogic relationship has not yet formed in social media, these provinces are concerned about collecting public needs. Seven provinces are located in this quadrant.

Mass media alterative, in the bottom-left quadrant, refers to low levels in both dimensions. 
This reveals that the potential of social media in risk communication is not fully exploited. Six provinces are located in this quadrant.

Table 5 Process and outcome measurement

\begin{tabular}{|c|c|c|c|}
\hline \multirow{2}{*}{$\begin{array}{c}\text { Provincial } \\
\text { administrative } \\
\text { unit }\end{array}$} & \multirow{2}{*}{$\begin{array}{c}\text { Outcome } \\
\begin{array}{c}\text { Public activity } \\
\text { matrix }\end{array} \\
\end{array}$} & \multicolumn{2}{|c|}{ Process } \\
\hline & & $\begin{array}{c}\text { Response rapidness } \\
\text { matrix }\end{array}$ & $\begin{array}{c}\text { Response attentiveness } \\
\text { matrix }\end{array}$ \\
\hline Beijing & Ghosts & Active responder & Intensive frequent posting \\
\hline Tianjin & Ghosts & Active responder & Prudent frequent posting \\
\hline Shanghai & Leaders & Active responder & Prudent frequent posting \\
\hline Chongqing & Leaders & Active responder & Intensive frequent posting \\
\hline Henan & Ghosts & Active follower & Intensive infrequent posting \\
\hline Hubei & Ghosts & Passive responder & Intensive frequent posting \\
\hline Jiangsu & Ghosts & Active responder & Prudent infrequent posting \\
\hline Jiangxi & Leaders & Active responder & Prudent frequent posting \\
\hline Jilin & Leaders & Active responder & Prudent infrequent posting \\
\hline Heilongjiang & Leaders & Active responder & Intensive frequent posting \\
\hline Shanxi & Leaders & Passive responder & Prudent frequent posting \\
\hline Shandong & Ghosts & Active follower & Prudent infrequent posting \\
\hline Qinghai & Ghosts & Active responder & Intensive infrequent posting \\
\hline Guangdong & Leaders & Active responder & Intensive infrequent posting \\
\hline Guizhou & Leaders & Active follower & Intensive infrequent posting \\
\hline Zhejiang & Leaders & Active responder & Prudent infrequent posting \\
\hline Xinjiang & Ghosts & Passive responder & Prudent infrequent posting \\
\hline
\end{tabular}

\section{Discussion}

The analytics offers a prototype observation of how to integrate the "speak from power" process with the "speak to power" outcome to understand the impact of social media on risk communication. Several findings from our analysis are worth noting.

The analysis results confirm that neither the outcome-centric nor the process-centric method alone cannot render a full picture of government-public interconnectivity during risk 
communication, which further corroborates our research motivation. Previous research (Agostino \& Arnaboldi, 2016; Bonsón \& Ratkai, 2013; Gerlitz \& Helmond, 2013; Pérez et al., 2012; Snead, 2013) posited that measurement of the government's performance can be achieved through the investigation of public activity. However, our first-hand evidence, based on real cases, contradicts this argument. For instance, Henan and Shanxi are both identified as Ghosts using the outcomecentric measurement but have opposite measurements in the process indicators. Henan is identified as an active follower in response rapidness and intensive infrequent posting in response attentiveness, while Shanxi is identified as a passive responder in response rapidness and prudent frequent posting in response attentiveness. The outcome cannot, therefore, be simplified as the mirror of the process but should be treated as a barometer of the cumulative influences of the process. Similarly, this also implies that the process-centric only method does not provide a better vision than the outcome-centric method. For example, Beijing and Chongqing, with identical performances in the process, ended up diametric in their outcomes (Ghosts and Leaders respectively). In sum, both reiterate the notion that, that the outcome and process have not yet formed a causality or are connected in a weak linear relevance but have complex interconnectivity.

This further underlines the need that the impact of social media on risk communication should and must be assessed through a combination of process and outcome, or interconnectivity. The dialogic theory posited that true connectivity requires the generation of mutuality (Kent $\&$ Taylor, 2002). As such, we argued that analyzing the correlation of "speak to power" and "speak from power" can provide nuanced insights into the impact of social media on risk communication. For instance, Chongqing and Heilongiiang are at high levels in both dimensions. This suggested that the likely formation of government-public mutuality in that two provinces, which further implies a government-public dialogic relationship. On the other hand, if only one dimension of the 
interconnectivity matrix is at a high level, it indicates that social media is majorly dominated by such dimensions. For instance, Beijing and Tianjin are located "speakfrom power" booster, which is high level in "speak from power" but the low level in "speak to power", suggesting that the social media function is dominated by "speak from power" and the "speak to power" potential is not fully exploited. Similarly, seven provinces are located in the "speak to power" channel, which is high level in "speak to power" but the low level in "speak from power", suggesting that the major function of social media is dominated by "speak to power" and the "speak from power potential is not fully exploited. These findings again corroborate our critique of existing research - a piecemeal, outcome-centric approach, rather than a systematic evaluation of risk communication, cannot readily shed light on the real situation.

The findings set out here also reveal the effectiveness of dialogic theory in understanding the focal issue. Specifically, the arguments advocated by Kent (2017) that social media has so far proven a poor dialogic tool and Norris and Moon (2005) argument that social media remains mostly a one-way "speak from power" strategy is directly challenged by the evidence from the results. Analytics in the Covid-19 response suggested a mutuality between the "speak from power" and "speak to power" in two provinces during the risk communication. Further investigations are required as it is necessary to refine the framework for an empirical investigation into the interconnectivity.

\section{Conclusion}

We used the dialogic theory as a theoretical lens through which to examine governmentpublic interconnectivity to provide nuanced insights into the impact of social media on risk communication. Specifically, the interconnectivity matrix that integrates "speakfrom power" with "speak to power" is introduced and the impact is measured through the correlation of the levels in 
the two dimensions. The framework is validated by investigating the Weibo accounts of 17 provincial administrative units in China for risk communication during the Covid-19 response. The implications of this study are twofold.

Theoretically, this study proposed a framework to provide a holistic view of dialogic theory, which is verified to provide nuanced insights on the impact of social media based risk communication. Specifically, instead of focusing on one side of the communication, we are looking at the interconnectivity between two parties. Drawing on dialogic theory, we have witnessed empirical evidence showing that dialogue could also exist in social media under certain conditions. In particular, two provinces have reached a mutuality high level in both "speak to power" and "speak from power", showing signs of government-public interconnectivity. In relation to further development of dialogic theory, this study enriches the context of dialogic theory, explaining the relationship between organizations and the public and extending the scope of dialogic theory to risk communication, calling for follow-up efforts to better understand the interconnectivity of governments and the public. This will, in turn, promote theory development and empirical analysis.

Practically, we performed a dialogic theory-based prototype framework to assess the government-public interconnectivity during the Covid-19 response and found that social media can not only be exploited to boost information dissemination, but also solicit public feedbacks and ultimately initiate interactive government-public dialogues. Particularly during emergency responses, informing the public with accurate information and appropriately engaging them is arguably an effective approach to reduce public anxiety and enhance government credibility. Specifically, administrators should exploit social media platforms to actively initialize "dialogue", rapidly respond to public needs, and strategically adjust response intensity to enhance the 
performance of risk communication.

This study is not without its limitations. First, in addition to the main process and outcome phases, there are other influential factors (e.g., demographic information, pandemic information), which are not incorporated into our framework. This issue is likely to be addressed in future studies. Second, Covid-19 is a long-lasting crisis and the impact of social media on interconnectivity could be dynamic across different stages rather than static, which requires further investigation. Finally, although this study has acquired all the available Weibo data from provincial administrative units in China, it has been confronted with data limitations similar to those encountered by previous studies of social media data (e.g., Bertot et al. (2012); (Martí, Serrano-Estrada, \& NolascoCirugeda, 2019)). Further work on this is therefore necessary, considering another scenario and adopting alternative data. In all, the study is not meant to present an all-in-one solution to address the above-mentioned challenges, but rather establish a starting point to develop a broader repertoire of strategies and exploit the benefit of social media in risk communication.

\section{Reference}

Agostino, D., \& Arnaboldi, M. (2016). "A measurement framework for assessing the contribution of social media to public engagement: An empirical analysis on Facebook". Public Management Review, 18(9), 1289-1307.

Agozzino, A. J. P. r. j. (2015). "Dialogic Communication Through "Pinning": An Analysis of Top 10 Most Followed Organizations Pinterest Profiles". 9(3), 1-13.

Al-Saggaf, Y., \& Simmons, P. (2015). "Social media in Saudi Arabia: Exploring its use during two natural disasters". Technological Forecasting and Social Change, 95, 3-15.

Alvarez, R. M., \& Hall, T. E. (2003). Point, click, and vote: The future of Internet voting. Brookings Institution Press. Washington, D.C.

Beaunoyer, E., Dupéré, S., \& Guitton, M. J. (2020). "COVID-19 and digital inequalities: Reciprocal impacts and mitigation strategies". Computers in Human Behavior, 111, 106424.

Bekkers, V., Edwards, A., Moody, R., \& Beunders, H. (2011). "Caught by surprise? Micromobilization, new media and the management of strategic surprises". Public Management Review, 13(7), 1003-1021.

Bertot, J. C., Jaeger, P. T., \& Hansen, D. (2012). "The impact of polices on government social media usage: Issues, challenges, and recommendations". Government information quarterly, 29(1), $30-40$.

Blumler, J., \& Gurevitch, M. (2002). The crisis of public communication. Routledge. Oxfordshire, UK.

Bonsón, E., \& Ratkai, M. (2013). "A set of metrics to assess stakeholder engagement and social legitimacy on a corporate Facebook page". Online Information Review, 37(5), 787-803. 
Borrino, R., Furini, M., \& Roccetti, M. (2009, Apr 20). Augmenting social media accessibility. Paper presented at the Proceedings of the 2009 International Cross-Disciplinary Conference on Web Accessibililty (W4A).

Bovaird, T. (2007). "Beyond engagement and participation: User and community coproduction of public services". Public administration review, 67(5), 846-860.

Buber, M. (1923). I and Thou. Touchstone. New York, US.

Dabner, N. (2012). "'Breaking Ground'in the use of social media: A case study of a university earthquake response to inform educational design with Facebook". The Internet and Higher Education, 15(1), 69-78.

DiClemente, R. J., \& Jackson, J. M. (2016). Risk communication. In International Encyclopedia of Public Health (pp. 378-382): Elsevier Inc. Amsterdam, Netherlands.

Facebook. (2021). Facebook Reports Second Quarter 2021 Results. Retrieved from https://investor.fb.com/investor-news/press-release-details/2021/facebook-reports-second-quarter2021-results/default.aspx

Feeney, M. K., \& Porumbescu, G. (2020). "The Limits of Social Media for Public Administration Research and Practice". Public administration review, 81(4), 787-792.

Feeney, M. K., \& Welch, E. W. (2012). "Electronic participation technologies and perceived outcomes for local government managers". Public Management Review, 14(6), 815-833.

Gerlitz, C., \& Helmond, A. (2013). "The like economy: Social buttons and the data-intensive web". New media \& society, 15(8), 1348-1365.

Gordon, J., \& Berhow, S. (2009). "University websites and dialogic features for building relationships with potential students". Public relations review, 35(2), 150-152.

Hand, L. C., \& Ching, B. D. (2011). "' You Have One Friend Request" An Exploration of Power and Citizen Engagement in Local Governments' Use of Social Media". Administrative Theory \& Praxis, 33(3), 362-382.

Haro-de-Rosario, A., Sáez-Martín, A., \& del Carmen Caba-Pérez, M. (2018). "Using social media to enhance citizen engagement with local government: Twitter or Facebook?". New media \& society, 20(1), 29-49.

Honnibal, M., \& Montani, I. (2017). "spaCy 2: Natural language understanding with Bloom embeddings, convolutional neural networks and incremental parsing". To appear, 7(1), 411-420.

Inauen, S., Schoeneborn, D., \& Scherer, A. G. (2011). "Twitter and its Usage for Dialogic Stakeholder Communication by MNCs and NGOs". SSRN Electronic Journal, 6.

Irwin, A. (2021). Risk, science and public communication: Third-order thinking about scientific culture. In Routledge handbook of public communication of science and technology (pp. 147-162): Routledge. Oxfordshire, UK.

Ju, I., Ohs, J., Park, T., \& Hinsley, A. (2021). "Interpersonal Communication Influence on Health-Protective Behaviors amid the COVID-19 Crisis". Health communication, 1-12.

Kavanaugh, A. L., Fox, E. A., Sheetz, S. D., Yang, S., Li, L. T., Shoemaker, D. J., . . X Xie, L. (2012). "Social media use by government: From the routine to the critical". Government information quarterly, 29(4), 480-491.

Kent, M. L. (2017). "Principles of dialogue and the history of dialogic theory in public relations". Prospect of public relations science, 105-129.

Kent, M. L., \& Taylor, M. (1998). "Building dialogic relationships through the World Wide Web". Public relations review, 24(3), 321-334.

Kent, M. L., \& Taylor, M. (2002). "Toward a Dialogic Theory of Public Relations". Public relations review, 28(1), 21-37.

Kim, S. K., Park, M. J., \& Rho, J. J. (2015). "Effect of the Government's Use of Social Media on the Reliability of the Government: Focus on Twitter". Public Management Review, 17(3), 328355 .

Ksiazek, T. B., Peer, L., \& Lessard, K. (2016). "User engagement with online news: Conceptualizing interactivity and exploring the relationship between online news videos and user comments". New media \& society, 18(3), 502-520.

Lee, G., \& Kwak, Y. H. (2012). "An open government maturity model for social media-based public engagement". Government information quarterly, 29(4), 492-503. 
Liao, Q., Yuan, J., Dong, M., Yang, L., Fielding, R., \& Lam, W. W. T. (2020). "Public Engagement and Government Responsiveness in the Communications About COVID-19 During the Early Epidemic Stage in China: Infodemiology Study on Social Media Data". J Med Internet Res, 22(5), e18796.

Lindell, M. K., \& Perry, R. W. (1992). Behavioral foundations of community emergency planning. Hemisphere Publishing Corp. London, England.

Lovari, A., \& Bowen, S. A. (2019). "Social media in disaster communication: A case study of strategies, barriers, and ethical implications". Journal of Public Affairs, 20(1), 9.

Ma, L. (2013). "The diffusion of government microblogging: Evidence from Chinese municipal police bureaus". Public Management Review, 15(2), 288-309.

Machmud, M., Irawan, B., Karinda, K., \& Susilo, J. (2021). "Analysis of the Intensity of Communication and Coordination of Government Officials on Twitter Social Media during the Covid-19 Handling in Indonesia". Academic Journal of Interdisciplinary Studies, 10(3), 319-319.

Martí, P., Serrano-Estrada, L., \& Nolasco-Cirugeda, A. (2019). "Social media data: Challenges, opportunities and limitations in urban studies". Computers, Environment and Urban Systems, 74, 161-174.

McAllister-Spooner, S. M. (2009). "Fulfilling the dialogic promise: A ten-year reflective survey on dialogic Internet principles". Public relations review, 35(3), 320-322.

Mergel, I. (2013). "A framework for interpreting social media interactions in the public sector". Government information quarterly, 30(4), 327-334.

Mondak, J. J. (1995). "Media exposure and political discussion in US elections". The Journal of Politics, 57(1), 62-85.

Nature. (2020). Coronavirus: the first three months as it happened. Retrieved from https://www.nature.com/articles/d41586-020-00154-w

Noddings, N. (1986). Caring: A Feminine Approach to Ethics and Moral Education. University of California Press. Oakland, CA.

Norris, D. F., \& Moon, M. J. (2005). "Advancing e-government at the grassroots: Tortoise or hare?". Public administration review, 65(1), 64-75.

NRP.org. (2020a). Chinese Authorities Begin Quarantine Of Wuhan City As Coronavirus Cases Multiply. Retrieved from https://www.npr.org/2020/01/23/798789671/chinese-authoritiesbegin-quarantine-of-wuhan-city-as-coronavirus-cases-multiply

NRP.org. (2020b). New Coronavirus Disease Officially Named COVID-19 By The World Health Organization.

Retrieved from

https://www.npr.org/sections/goatsandsoda/2020/02/11/802352351/new-coronavirus-gets-anofficial-name-from-the-world-health-organization

Palen, L., \& Liu, S. B. (2007). Citizen communications in crisis: anticipating a future of ICTsupported public participation. Paper presented at the Proceedings of the SIGCHI conference on Human factors in computing systems, New York, NY.

Pearson, R. A. (1990). A theory of public relations ethics. (Doctoral), Ohio University, Athens, $\mathrm{OH}$.

Pérez, C. C., Bolívar, M. P. R., \& Hernández, A. M. L. (2012). The use of Web 2.0 to transform public services delivery: The case of Spain. In Web 2.0 Technologies and Democratic Governance (pp. 41-61): Springer. New York, NY.

Picazo-Vela, S., Gutiérrez-Martínez, I., \& Luna-Reyes, L. F. (2012). "Understanding risks, benefits, and strategic alternatives of social media applications in the public sector". Government information quarterly, 29(4), 504-511.

Pourebrahim, N., Sultana, S., Edwards, J., Gochanour, A., \& Mohanty, S. (2019). "Understanding communication dynamics on Twitter during natural disasters: A case study of Hurricane Sandy". International Journal of Disaster Risk Reduction, 37, 101176.

Rishika, R., Kumar, A., Janakiraman, R., \& Bezawada, R. (2013). "The effect of customers' social media participation on customer visit frequency and profitability: an empirical investigation". Information systems research, 24(1), 108-127.

Rogers, C. R. (1957). "The necessary and sufficient conditions of therapeutic personality change". J Consult Psychol, 21(2), 95-103. 
Rowe, G., \& Frewer, L. J. (2000). "Public participation methods: A framework for evaluation". Science, technology, \& human values, 25(1), 3-29.

Rybalko, S., \& Seltzer, T. (2010). "Dialogic communication in 140 characters or less: How Fortune 500 companies engage stakeholders using Twitter". Public relations review, 36(4), 336341.

Shan, S., Wang, L., Li, L., \& Chen, Y. (2012). "An emergency response decision support system framework for application in e-government". Information Technology and Management, 13(4), 411-427.

Silver, A., \& Matthews, L. (2017). "The use of Facebook for information seeking, decision support, and self-organization following a significant disaster". Information, Communication \& Society, 20(11), 1680-1697.

Şirin, H., \& Özkan, S. (2021). Risk Communication and Media in Pandemics. In Handbook of Research on Representing Health and Medicine in Modern Media (pp. 140-149): IGI Global. Ankara, Turkey.

Snead, J. T. (2013). "Social media use in the US Executive branch". Government information quarterly, 30(1), 56-63.

Snyder, D., \& Kelly, W. R. (1977). "Conflict intensity, media sensitivity and the validity of newspaper data". American Sociological Review, 105-123.

Sommerfeldt, E. J., \& Yang, A. (2018). Notes on a dialogue: Twenty years of digital dialogic communication research in public relations. In. Milton Park, Oxfordshire: Taylor \& Francis.

Tajudeen, F. P., Jaafar, N. I., \& Sulaiman, A. (2016). "Role of social media on information accessibility". Pacific Asia Journal of the Association for Information Systems, 8(4), 3.

Tolbert, C. J., \& Mossberger, K. (2006). "The effects of e-government on trust and confidence in government". Public administration review, 66(3), 354-369.

Torero, M. (2020). Without food, there can be no exit from the pandemic. In. London, UK: Nature Publishing Group.

Wang, X., \& Wan Wart, M. (2007). "When public participation in administration leads to trust: An empirical assessment of managers' perceptions". Public administration review, 67(2), 265-278.

Warren, A. M., Sulaiman, A., \& Jaafar, N. I. (2014). "Social media effects on fostering online civic engagement and building citizen trust and trust in institutions". Government information quarterly, 31(2), 291-301.

WeiboCorporation. (2020, November 14, 2020). Weibo Reports First Quarter 2020 Unaudited Financial Results. Retrieved from https://weibocorporation.gcs-web.com/news-releases/newsrelease-details/weibo-reports-third-quarter-2019-unaudited-financial-results

Welch, E. W., Hinnant, C. C., \& Moon, M. J. (2005). "Linking citizen satisfaction with egovernment and trust in government". Journal of public administration research and theory, 15(3), 371-391.

WHO. (2020). Statement on the second meeting of the International Health Regulations (2005) Emergency Committee regarding the outbreak of novel coronavirus (2019-nCoV). Retrieved from https://www.who.int/news-room/detail/30-01-2020-statement-on-the-second-meeting-of-theinternational-health-regulations-(2005)-emergency-committee-regarding-the-outbreak-of-novelcoronavirus-(2019-ncov)

XinhuaNet. (2020a). Top-level response to coronavirus activated in 30 Chinese provinciallevel regions. Retrieved from http://www.xinhuanet.com/english/2020-01/26/c 138734639.htm

XinhuaNet. (2020b). Xi orders resolute efforts to curb virus spread. Retrieved from http://www.xinhuanet.com/english/2020-01/20/c 138721535.htm

$\mathrm{Xu}$, J., Kang, Q., Song, Z., \& Clarke, C. P. (2015). "Applications of mobile social media: WeChat among academic libraries in China". The Journal of Academic Librarianship, 41(1), 2130.

Yan, L., \& Pedraza-Martinez, A. (2019). "Social media for disaster management: Operational value of the social conversation". Production Operations Management, 28(10), 2514-2532.

Zavattaro, S. M., \& Sementelli, A. J. (2014). "A critical examination of social media adoption in government: Introducing omnipresence". Government information quarterly, 31(2), 257-264.

Zheng, L., \& Zheng, T. (2014). "Innovation through social media in the public sector: 
Information and interactions". Government information quarterly, 31, S106-S117. 


\section{Appendix 1 Demographics and characteristics of each province}

\begin{tabular}{ccccc}
\hline & $\begin{array}{c}\text { GDP } \\
(2020)\end{array}$ & $\begin{array}{c}\text { Population } \\
(2019)\end{array}$ & $\begin{array}{c}\text { Urbanization } \\
\text { Rate }\end{array}$ & $\begin{array}{c}\text { Proximity to } \\
\text { Hubei }\end{array}$ \\
\hline Province & (Trillion yuan) & Million & $\%$ & $>1000 \mathrm{~km}$ \\
\hline Beijing & 3.61 & 21.54 & 86.60 & $>1000 \mathrm{~km}$ \\
Tianjin & 1.40 & 15.62 & 83.48 & $<1000 \mathrm{~km}$ \\
Shanghai & 3.87 & 24.28 & 88.30 & Adjacency \\
Chongqing & 2.50 & 31.24 & 66.80 & Adjacency \\
Henan & 5.50 & 96.40 & 53.21 & N/A \\
Hubei & 4.34 & 59.27 & 61.00 & Adjacency \\
Jiangsu & 10.27 & 80.70 & 70.61 & Adjacency \\
Jiangxi & 2.57 & 46.67 & 57.42 & $>1000 \mathrm{~km}$ \\
Jilin & 1.23 & 26.90 & 58.27 & $>1000 \mathrm{~km}$ \\
Heilongjiang & 1.37 & 37.51 & 60.90 & $<1000 \mathrm{~km}$ \\
Shanxi & 1.77 & 37.29 & 59.55 & $>1000 \mathrm{~km}$ \\
Shandong & 7.31 & 100.70 & 61.51 & $<1000 \mathrm{~km}$ \\
Qinghai & 0.30 & 6.07 & 55.52 & $<1000 \mathrm{~km}$ \\
Guangdong & 11.08 & 115.21 & 71.40 & $<1000 \mathrm{~km}$ \\
Guizhou & 1.78 & 36.23 & 49.02 & $>1000 \mathrm{~km}$ \\
Zhejiang & 6.46 & 58.50 & 70.00 & \\
Xinjiang & 1.38 & 25.23 & 51.87 & \\
\hline
\end{tabular}

Resource: The official website of the provincial statistics bureaus. 